DOI: 10.21680/2447-7842.2021v7n1ID24004

\title{
Programa Biblioteca Jurídica da Escola da Magistratura do Rio Grande Do Norte
}

Legal Library Program of The Rio Grande do Norte Magistrature School

\author{
Ana Cláudia Carvalho de Miranda ${ }^{1}$ (D) \\ <ianaclaudia@tirn.jus.br> \\ Michelly Dourado Ângelo ${ }^{2}$ \\ <michellydourado@hotmail.com.br> \\ Monica Marques Carvalho Gallotti ${ }^{3}$ \\ <monica_mcg@hotmail.comr>
}

Submetido em: 08-02-2021

Aceito em:13-08-2021

Resumo: $\mathrm{O}$ artigo tem como objetivo propor um estudo de usuários com a finalidade de analisar a satisfação dos magistrados no contexto da Biblioteca da Escola da Magistratura do Rio Grande do Norte (Esmarn), no tocante ao Programa Biblioteca Jurídica (PBJ), o qual propõe estratégias que visem à aquisição de material bibliográfico e não bibliográfico nesse contexto e a consequente socialização das informações jurídicas na referida instituição. Para contextualizar o assunto, fez-se uma pesquisa bibliográfica abordando temas transversais, como informação jurídica e estudo de usuários. Com vistas a detalhar o locus da pesquisa, fez-se uma descrição da referida escola quanto aos seus aspectos históricos, à caracterização, à sua unidade de informação e ao referido programa, seus objetivos, entre outros aspectos. A metodologia da pesquisa é do tipo descritiva, com abordagem de cunho quantitativo. Quanto à

\footnotetext{
${ }^{1}$ Mestre em Administração - UFRN. Graduada em Biblioteconomia - UFC.

${ }^{2}$ Graduação em andamento em Biblioteconomia - UFRN.

${ }^{3}$ Doutora em Informação e Comunicação em Plataformas Digitais - U.PORTO. Mestre em Ciência da Informação - UFPB. Graduada em Biblioteconomia - UFPB.
} 
parte empírica do trabalho, a pesquisa caracterizou a comunidade de usuários com o intuito de analisar o nível de satisfação relativo aos diferentes aspectos do PBJ. Os dados foram coletados por meio de questionário aplicado à população de usuários do programa (magistrados). No final, foi possível inferir que o programa foi avaliado de forma satisfatória pelos magistrados, que cumprem sua função precípua - a de promover o acesso a uma informação jurídica de boa qualidade. Por fim, indica-se a necessidade de avaliações periódicas do programa visando garantir a prestação de serviços de boa qualidade e o cumprimento dos objetivos organizacionais, bem como conferir transparência ao uso de recursos públicos.

Palavras-chave: Programa Biblioteca Jurídica. Estudo de usuários. Informação Jurídica - Escola da Magistratura do RN.

\section{INTRODUÇÃO}

A informação tem sido - ao longo do tempo - um recurso fundamental na sociedade. Há muitos séculos, tem assumido um protagonismo à medida que se configura como base para processos de evolução social, política e econômica. Quando bem empregada, organizada e processada, é capaz de produzir inovação em variados setores.

A informação se apresenta de forma complexa no contexto atual, assumindo diversas tipologias para uso em variados suportes. Dentre as tipologias existentes, tem-se a informação jurídica, originada, fundamentalmente, por meio de um tripé informacional distinto: legislação, doutrina e jurisprudência. Legislação se traduz em um conjunto normativo que regula a convivência social, elaborada pelo Poder Legislativo dos municípios, dos estados e da União (MIRANDA; D'AMARE; PINTO, 2013). Esse tipo de informação é utilizado, predominantemente, em unidades de informação jurídica ou espaços acadêmicos, tais como escolas da magistratura. 


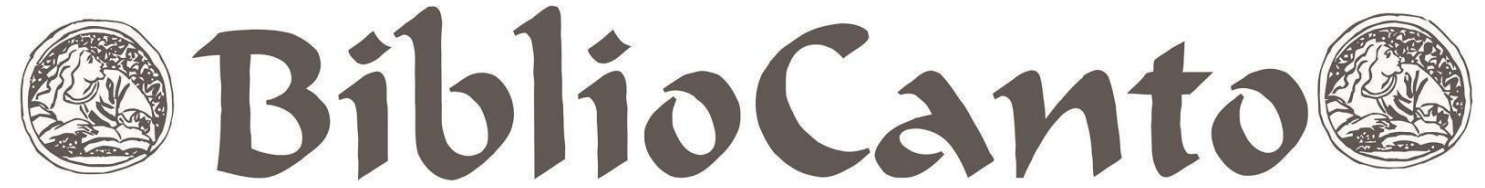

62

No Brasil, as escolas da magistratura são reconhecidas como instituições que desempenham importante papel no aperfeiçoamento e na capacitação dos magistrados (programas de treinamento e cursos de formação, no decorrer do período de vitaliciamento dos juízes) e contribuem com o processo de incorporação de novos juízes à carreira. Koury (2010, p. 5) reforça a importância das escolas judiciais, ao afirmar que,

Em se tratando da formação dos juízes, cabe às escolas judiciais suprir essas lacunas na formação, o que, por certo, contribui para que sejam atingidos os objetivos estratégicos do Poder Judiciário, devendo voltar-se para a formação de juízes.

O aprimoramento intelectual da magistratura há de ser constantemente buscado por organizações públicas nas quais se encontram inseridos os magistrados, tais como os tribunais de Justiça. Tal aprimoramento só será possível com ações de acesso à informação e processos educativos diversos, com vistas a gerar uma aprendizagem significativa por parte dos sujeitos.

Como forma de articular os saberes nesse campo, existem as bibliotecas jurídicas especializadas. Esse tipo de unidade de informação tem a função primordial de ofertar serviços de mediação da informação jurídica para atender a uma população de usuários também especializada em determinado domínio do conhecimento.

A atualização de conhecimentos reflete-se na qualidade da prestação jurisdicional com significativos impactos sociais. Por outro lado, as constantes alterações legislativas e a própria evolução da Ciência do Direito impõem aos juízes a necessidade de atualização constante (por meio de cursos e processos educativos), bem como a aquisição de materiais informacionais.

A informação jurídica passa por alterações na legislação, e a doutrina e a jurisprudência também sofrem mudanças significativas. Isso afeta sobremaneira profissionais cujo objeto de trabalho é a informação jurídica, entre os quais se destacam: magistrados, promotores, procuradores, defensores públicos, delegados, advogados, bem como profissionais da informação. Com o intuito de aprimorar os serviços e o atendimento às 


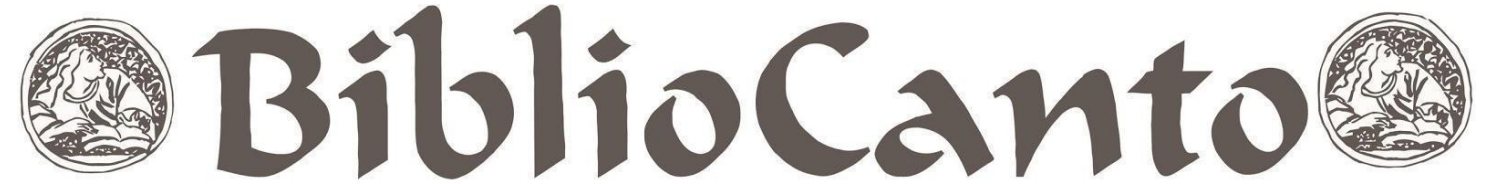

63

necessidades de informação nesse contexto, é necessário criar produtos e projetos que atendam às especificidades dessa realidade. Dessa forma, elaboram-se estratégias, serviços no âmbito das bibliotecas jurídicas, tais como o Programa Biblioteca Jurídica (PBJ), criado com a finalidade de aparelhar as unidades jurisdicionais do Rio Grande do Norte (RN), com coleções bibliográficas, e com o objetivo atender às necessidades informacionais dos juízes e dos assessores para auxiliar as decisões judiciais que nesse contexto constituem a comunidade de usuários.

Com o propósito de caracterizar a referida comunidade de usuários, bem como analisar criticamente o programa supracitado, foram levantados os seguintes questionamentos: Qual o perfil dos magistrados do RN? O PBJ tem alcançado os objetivos a que se propõe? Quais as possíveis melhorias a serem implementadas neste âmbito?

O trabalho em tela tem por objetivo realizar um estudo de usuários, com a finalidade de analisar a satisfação dos magistrados do Poder Judiciário do estado Rio Grande do Norte em relação ao PBJ.

Partindo-se dessa premissa, traçaram-se os seguintes objetivos específicos: (i) indicar os principais conceitos relativos à área de estudo de usuários; (ii) apontar as características históricas da Esmarn; (iii) caracterizar o PBJ, identificar suas fases e apresentar melhorias a serem inseridas no programa, bem como no processo de atendimento às necessidades informacionais nesse contexto.

A realização do trabalho justifica-se pela inexistência de pesquisas que analisem o grau de satisfação com programas desse tipo. Tais avaliações auxiliam a tomada de decisão e o atendimento aos objetivos institucionais, conferindo mais transparência no emprego de recursos públicos. Adicionalmente, é relevante perceber o papel da biblioteca da Esmarn no desenvolvimento do referido programa a fim de perceber dificuldades e as lacunas informacionais por parte de seus usuários do Poder Judiciário, com o objetivo de formar e adequar o acervo para atender às suas demandas e conhecer seu grau de satisfação. 


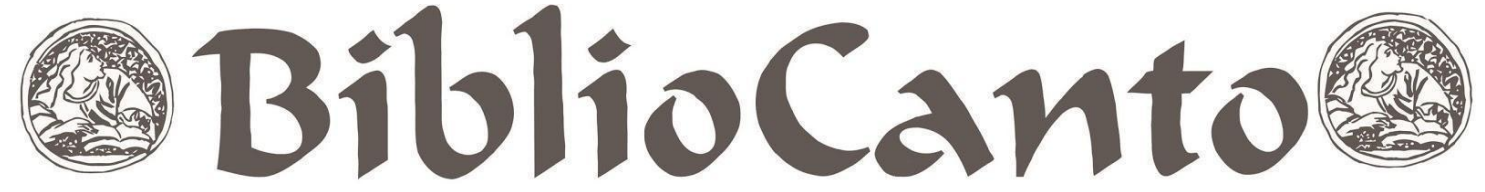

64

É importante ressaltar que os estudos de usuários vêm sendo aplicados em várias unidades informacionais, para avaliar e validar atividades, projetos e serviços, bem como com o intuito de justificar a aplicação de recursos e propor melhorias em suas atividades. Além do exposto, a socialização dos resultados pode possibilitar a reprodutibilidade da metodologia utilizada em outras bibliotecas jurídicas com características semelhantes.

Antes de se reportar aos aspectos centrais do trabalho, convém contextualizar o assunto visando a um entendimento global. Para isso, inicia-se com esclarecimentos relativos à informação jurídica, ao seu escopo e aos objetivos. Em seguida, tecem-se algumas considerações sobre os aspectos relativos ao estudo de usuários, partindo-se para aspectos descritivos quanto ao locus da pesquisa, os dados coletados e forma de análise.

\section{INFORMAÇÃO JURÍDICA}

Como visto na introdução, a informação movimenta o rumo das decisões nos inúmeros segmentos da sociedade. No contexto das unidades de informação, como as bibliotecas, esse recurso é a matéria-prima e, ao mesmo tempo, configura-se como um objeto central de suas práticas. É claro que essa assertiva é extensível aos diversos ramos da ciência, porém, no campo da Ciência Jurídica, a informação colabora para a produção de doutrinas, fundamentação das petições, elaboração das leis, pareceres, formulação das sentenças, jurisprudências, súmulas, entre outras ações jurídicas necessárias.

Barros (2004, p. 205) define esse tipo de informação como aquela "contida numa lei, decreto, decisão, artigo doutrinário, portaria etc." e o "alicerce" para o ofício dos profissionais do Direito. O autor considera a informação jurídica útil para o progresso da cidadania, uma vez que é gerada pelos profissionais do Direito com suas decisões voltadas para regulamentar o cumprimento da justiça na sociedade.

Nesse contexto, a informação jurídica detém uma função social, porque estabelece uma regulamentação que interfere diretamente na vida da 
sociedade, portanto deve estar acessível ao público a que se destina. Devido ao seu caráter público, a informação jurídica tem as funções de possibilitar aos cidadãos o discernimento das regras, dos direitos e dos deveres que regulam a sociedade e de propiciar a disseminação e a transparência das ações executadas pelo poder público.

Para Guimarães (1999, p. 11), a informação jurídica é interpretada como "o conjunto de conteúdos pertencentes ao universo conceitual da Ciência Jurídica, que se expressam por meio das formas documentárias reveladoras da atuação jurídica". Na área jurídica, o aumento de novos conteúdos publicados nos últimos anos tem tomado grandes proporções, porquanto a produção de informação jurídica tem ampliado dimensões e acelerado a elaboração doutrinária e a publicação de leis. De acordo com Miranda e Miranda (2017), em virtude do desenvolvimento tecnológico, muitas são as situações novas que exigem dos juristas e dos elaboradores das leis uma produção maior de normas e interpretação doutrinária para atuar a contento com condutas inovadoras.

A concepção teórica apresentada, neste trabalho, acerca da informação jurídica, corrobora o pensamento de Passos (1994), que define esse tipo de informação como toda unidade do conhecimento humano que tem o propósito de fundamentar exposições do pensamento daqueles que operam com a matéria jurídica. No entanto, essa definição não diz respeito somente à teoria pura ou à Filosofia do Direito, mas também a todas as áreas do conhecimento que estão se fundindo com as Ciências Jurídicas, o que nos leva a inferir que a área jurídica é, essencialmente, uma área epistêmica interdisciplinar.

De acordo com Atienza (1979), Passos (1994), Guimarães (1999), Barros (2004), Miranda, D’Amore e Pinto (2013), a apresentação da informação jurídica é originada deste tripé informacional distinto:

1. Legislação: conjunto normativo de leis que norteiam a convivência social, emanado do Poder Legislativo dos municípios, dos estados e da União. 


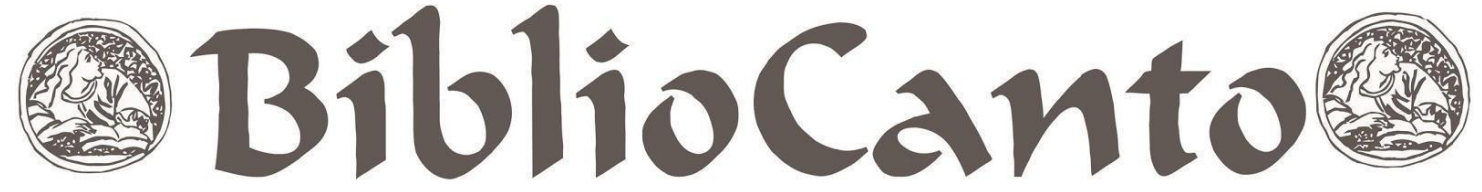

2. Doutrina: conjunto de princípios expostos nas obras de Direito, em que se firmam teorias ou se interpreta o conhecimento jurídico realizado por especialistas da área e exteriorizado em caráter científico.

3. Jurisprudência: é a sábia interpretação e aplicação das leis a todos os casos concretos que se submetem a julgamento da Justiça, que produz sentenças, no primeiro grau, ou acórdãos e súmulas dos tribunais com uniformidade de entendimento.

$\mathrm{Na}$ sociedade contemporânea, a disseminação da informação jurídica acompanha as evoluções tecnológicas, que se manifestam por meio de plataformas digitais complexas, representadas por uma miríade de fontes de informação digitais, tais como páginas da web, de sites dos tribunais e do Diário Oficial, mensagens de correio eletrônico, e-books, bibliotecas virtuais e digitais, periódicos eletrônicos disponíveis em bases de dados jurídicas, livros, monografias, súmulas, coletânea de textos legais, entre outros. O universo da informação jurídica produzida tem aumentado exponencialmente devido às constantes alterações (derrogações e revogações) na legislação, o que, consequentemente, modifica o conjunto sistemático do Direito, que, por sua vez, origina inúmeras jurisprudências e súmulas.

As bibliotecas, de forma geral, são responsáveis por organizar, catalogar, indexar, classificar e disseminar a informação e o conhecimento. Já as bibliotecas jurídicas - por sua vez - buscam difundir a informação jurídica, especialmente na esfera de suas instituições mantenedoras, com o intuito de subsidiar as decisões processuais em fluxo e de auxiliar todos os juristas a aplicarem justiça e, até, a criarem pensamento jurídico (MIRANDA; D'AMORE; PINTO, 2013).

Na concepção de Andrade (2017), a biblioteca jurídica é apontada como um verdadeiro serviço de informação, radicado no contexto da sociedade da informação e do conhecimento para todos, a fim de subsidiar a comunidade de usuários a que serve. Portanto, as bibliotecas jurídicas são originárias de órgãos governamentais, universidades ou escritórios de advocacia, e atuam como principal veículo disseminador das Ciências Jurídicas. Também 
contribuem para propagar doutrinas, leis, decretos, portarias, pareceres, sentenças e jurisprudências e com o exercício de magistrados, legisladores, membros do Ministério Público, defensores públicos ou advogados, que se utilizam dos estudos da informação jurídica para interpretar e aplicar os dispositivos legais na sustentação das teses, principalmente em casos semelhantes.

Por fim, pode-se dizer que esse tipo de unidade de informação exerce um papel fundamental e é considerada mola-mestra na necessária difusão da informação jurídica na sociedade. Para garantir o cumprimento dos seus objetivos, torna-se necessário acompanhar e monitorar constantemente as mudanças na legislação; diante disso, surge a necessidade de coleções atualizadas. Nesse contexto, as unidades de informação jurídica utilizam-se de estratégias, como o estudo de usuários.

\section{ESTUDO DE USUÁRIOS: CARACTERÍSTICAS E FUNÇÕES ${ }^{4}$}

Conforme indicado na seção anterior - e com vistas a promover um serviço de qualidade -, as unidades de informação recorrem a estratégias específicas para monitorar, analisar continuamente o uso da informação por parte de seus usuários e identificar, por meio de estudos, as necessidades de informação reais ou potenciais das comunidades.

Esse campo tem sido representado de forma crescente na literatura científica da área. Para Cunha, Amaral e Dantas (2015, p. 31), os primeiros estudos dessa natureza se iniciaram fora do Brasil. No início de sua aplicação, não eram chamados de estudos de usuários, mas de "levantamento de bibliotecário". Mais adiante, em meados do século XX, surgem definições com o termo estudo de usuários na literatura da Biblioteconomia e da Ciência da Informação.

\footnotetext{
${ }^{4}$ Não é objetivo deste estudo esgotar todas as possibilidades deste campo, uma vez que a literatura científica da área aponta excelentes contributos e avanços na temática.
} 
No início, o foco desse tipo de estudo era o uso de sistemas ou a identificação do tipo de fonte de informação utilizada, e não diretamente o usuário da informação ou como a informação impactava determinada comunidade (FIGUEIREDO, 1994). Mais adiante, em meados de 1980, deu-se início a um processo de transição para valorizar o usuário e começaram a ser aplicadas técnicas de pesquisa quantitativas e qualitativas adaptadas a esse universo. Há um avanço nesse tipo de estudo, sobretudo por meio de novos contributos, e o surgimento de modelos variados, como os propostos por Kuhlthau (1991) e Wilson (2006).

Um conceito de estudo de usuário é indicado por Araújo (2010, p. 25), que aponta essa área de estudo como:

[...] um campo desenvolvido ao longo de algumas décadas, com forte caráter empiricista, voltado para a aplicação de métodos prioritariamente quantitativos na busca de padrões e regularidades do comportamento dos usuários para o estabelecimento de leis "científicas" sobre o uso da informação.

Para Tarapanoff (2004, p. 120), o estudo de usuários é considerado:

[...] [uma] técnica utilizada para traçar o perfil de usuários de um determinado produto, serviço ou centro de documentação e a partir daí direcionar e padronizar o atendimento, melhorar a qualidade dos produtos oferecidos e atender da melhor maneira possível a demanda e a necessidade dos usuários.

Ambos os autores corroboram a premissa de que o objetivo desse tipo de estudo é traçar inferências e identificar padrões de comportamento comuns a determinada população de usuários. Então, com a identificação desses padrões, é possível planejar melhorias para atender às necessidades de informação e promover o design de propostas de serviços a serem realizadas.

Como se pode perceber, estudos desse tipo têm como foco os sujeitos informacionais, ou seja, indivíduos que precisam de informação e recorrem aos serviços de informação (ARAÚJO, 2013). Para Guinchat e Menou (1994, p. 481): 
O usuário é um elemento fundamental de todos os sistemas de informação, pois a única justificativa das atividades desses sistemas é a transferência de informações entre dois ou mais interlocutores distantes no espaço e no tempo.

Os mesmos autores reafirmam esse argumento quando indicam que "o usuário deve ser a base da orientação e da concepção das unidades e dos sistemas de informação, a serem definidos em função de suas características, de suas atitudes, de suas necessidades e de suas demandas" (GUINCHAT; MENOU, 1994, p. 482). Sem levar em conta as especificidades do contexto em que esses sujeitos estão inseridos, aferir (continuamente) suas percepções e indicar suas necessidades de informação, é inviável o planejamento de serviços de informação em unidades de informação. Ainda segundo Figueiredo (1994), o valor desse tipo de estudo consiste em identificar, para além das necessidades de informação, a forma e a finalidade da informação utilizada pelo usuário e quais os fatores que afetam esse uso. Tais medidas ainda contribuem para cobrir o espectro total das atividades entre os gestores, a coleção, os serviços dispensados e os usuários.

Segundo González Teruel (2005), para cada grupo de usuários, existem características que abrangem o todo e as que são próprias de cada sujeito. Nesse contexto, é primordial que se façam estudos que indiquem essas semelhanças e as diferenças, a fim de satisfazer às necessidades de informação e de promover serviços contextualizados de acordo com a realidade em que estão inseridos esses sujeitos. $\mathrm{Na}$ próxima seção, descrever-se-á o locus da pesquisa.

\section{ESMARN: CARACTERIZAÇÃO E ASPECTOS HISTÓRICOS}

Órgão do Tribunal de Justiça do Estado do Rio Grande do Norte (TJRN), a Escola da Magistratura do Rio Grande do Norte foi criada em $1^{\circ}$ de dezembro de 1988, por meio da Resolução $n^{\circ} 5 / 88$ do egrégio TJRN, publicada no Diário Oficial do Estado de 9 de dezembro de 1988, mesmo ano em que os três poderes passaram por profundas mudanças provocadas pela promulgação da 


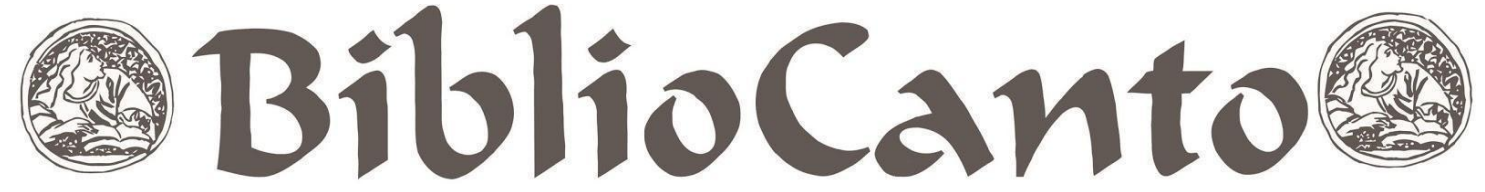

atual Constituição Federal (TRIBUNAL DE JUSTIÇA DO ESTADO DO RIO GRANDE DO NORTE, 1988).

A Esmarn foi idealizada com o objetivo de formar, capacitar e aperfeiçoar magistrados e servidores potiguares. Desde então, a instituição de ensino foi pautada por uma história marcada pelo pioneirismo e pelo reconhecimento da sociedade e tornou-se um modelo para as escolas de magistratura de outros estados do país.

Em 1990, o TJRN, por meio de ato do seu então presidente, desembargador Deusdedit Chaves Maia, editou o Regimento Interno da Esmarn, disciplinou seu funcionamento e criou conselhos, órgãos diretivos, coordenadorias, serviços, finalidades e manutenção orçamentária e financeira.

Com a edição da Lei Estadual n 6.370, de 20 de janeiro de 1993, que dispunha sobre a organização da Secretaria e dos serviços auxiliares do TJRN e definiu as diretrizes gerais para sua reforma e modernização administrativa, a Escola passou a ser considerada "órgão da administração desconcentrada" do Tribunal de Justiça (art. $3^{\circ}$ ), com disciplina institucional prevista no art. 42 da citada lei, mantido o seu Regimento Interno $\left(\S 3^{\circ}\right)$.

Dez anos depois de editar a Resolução n 5/1988, o TJRN regulamentou o Curso de Formação Inicial de Magistrados, por meio da Resolução n 7 , de 2 de setembro de 1998, que alterou significativamente a estrutura normativa da Escola, inclusive sua denominação, que passou a ser Escola da Magistratura do Rio Grande do Norte - Esmarn (TRIBUNAL DE JUSTIÇA DO RIO GRANDE DO NORTE, 1998). Esse processo institucional de construção de escolas judiciais e judiciárias foi reconhecido constitucionalmente com a Emenda $\mathrm{n}^{\circ}$ $45 / 2004$

, denominada de Reforma do Judiciário, que incluiu diversas modificações nas competências dos tribunais e previu a instituição de colegiados administrativos para o controle do Poder Judiciário e do Ministério Público, o Conselho Nacional de Justiça $(\mathrm{CNJ})$ e o Conselho Nacional do Ministério Público (CNMP). 


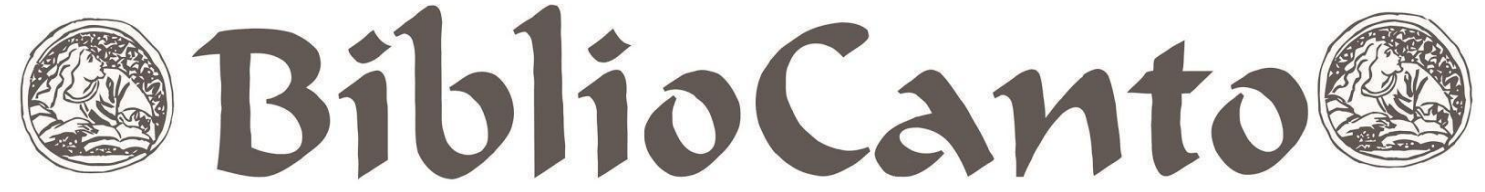

71

Nesse contexto, foi prevista a implementação de uma Escola Nacional de Formação e Aperfeiçoamento de Magistrados (Enfam), com a pretensão de se estruturar, na entidade central, um sistema brasileiro de formação e aperfeiçoamento de juízes, nos termos do inciso IV do art. 93 da Constituição da República Federativa do Brasil (CRFB). Contudo, devido ao novo papel das escolas judiciais no país, foi necessária uma gestão inovadora, porém segura e eficiente. Os desafios foram muitos para promover novos cursos, que contribuíram para o bom andamento dos trabalhos do seu corpo discente, constituído de magistrados, servidores e parceiros, em geral, do Poder Judiciário do RN.

Nessa perspectiva, a Esmarn avança com a implementação do projeto de vanguarda denominado Programa Residência Judicial (curso de pós-graduação lato sensu), desenvolvido em parceria com a Universidade Federal do Rio Grande de Norte (UFRN), representando a primeira iniciativa desse tipo no país. Além disso, dando continuidade à formação e à capacitação dos magistrados do Poder Judiciário Potiguar, a Esmarn, em parceria com a UFRN, oferta a turma especial de Mestrado em Direito. Portanto, trata-se de mais uma iniciativa pioneira no Brasil, no tocante a parcerias entre Escolas Judiciais e Instituições de Ensino Superior (IES), para cursos de pós-graduação stricto sensu na área jurídica.

Assim, tendo em vista a importância de preservar a memória institucional e de reconhecer devidamente as personalidades que prestaram relevantes serviços ao Judiciário potiguar, os desembargadores do TJRN, em sessão plenária por videoconferência, atribuíram à Esmarn o nome do desembargador Manoel de Araújo Silva, por meio da aprovação da Resolução n 8 -TJ/2020 (TRIBUNAL DE JUSTIÇA DO ESTADO DO RIO GRANDE DO NORTE, 2020).

A proposição foi feita pelo desembargador Saraiva Sobrinho, diretor da Esmarn, durante o Biênio 2019/2020, que destacou a contribuição do homenageado: "O notório saber do desembargador Manoel de Araújo Silva elevou o ensino técnico-jurídico direcionado aos magistrados e aos servidores, 


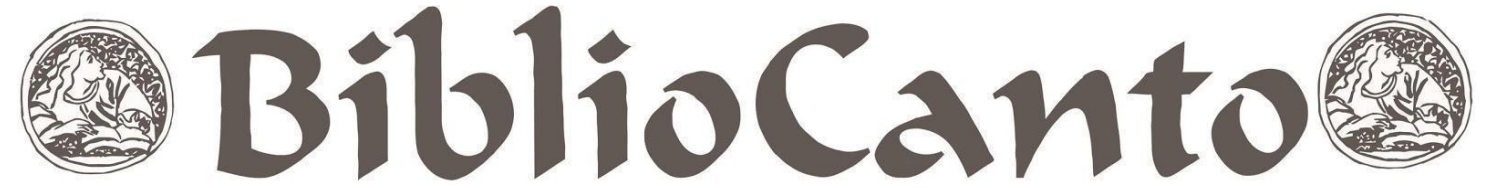

72

ao nível de excelência, contribuindo para que, hoje, a Escola seja referência nacional".

Finalmente, mas sem esgotar o histórico da Esmarn, destaque-se a criação do Programa Biblioteca Jurídica (PBJ), o qual visa aparelhar as unidades jurisdicionais com acervos bibliográficos, que por sua vez podem servir de insumo para os usuários do referido programa: os magistrados.

\subsection{BIBLIOTECA DA ESMARN}

Conforme destacado, as bibliotecas das escolas judiciais atuam como órgãos de apoio informacional, dando suporte às atividades de ensino e de pesquisa, com vistas a contextualizar as práticas dos magistrados. Seu diferencial em relação a outras unidades de informação é o fato de apoiar a formação continuada na área jurídica, sendo esta a principal característica desse tipo de instituição.

O principal papel das bibliotecas das escolas judiciais é atender às necessidades informacionais dos magistrados, dos servidores e do corpo docente e discente da escola, direcionando seu acervo aos conteúdos programáticos dos cursos ministrados pela escola em conformidade com as ações estratégicas do Tribunal na qual está inserida.

Nesse contexto, a Biblioteca Desembargador José Gomes da Costa, vinculada à Escola da Magistratura do Rio Grande Norte - Esmarn ${ }^{5}$, iniciou suas atividades em $1^{\circ}$ de dezembro de 1998.

\footnotetext{
${ }^{5}$ A Biblioteca Desembargador José Gomes da Costa funciona nos seguintes horários: de segunda a quinta-feira, das $8 \mathrm{~h}$ às $18 \mathrm{~h}$, e sexta-feira, das $8 \mathrm{~h}$ às $17 \mathrm{~h}$. Localiza-se na Rua Promotor Manoel Alves Pessoa Neto, 1000 - Candelária, Natal/RN, 59065-555.
} 
Foto 1 - Prédio da Esmarn

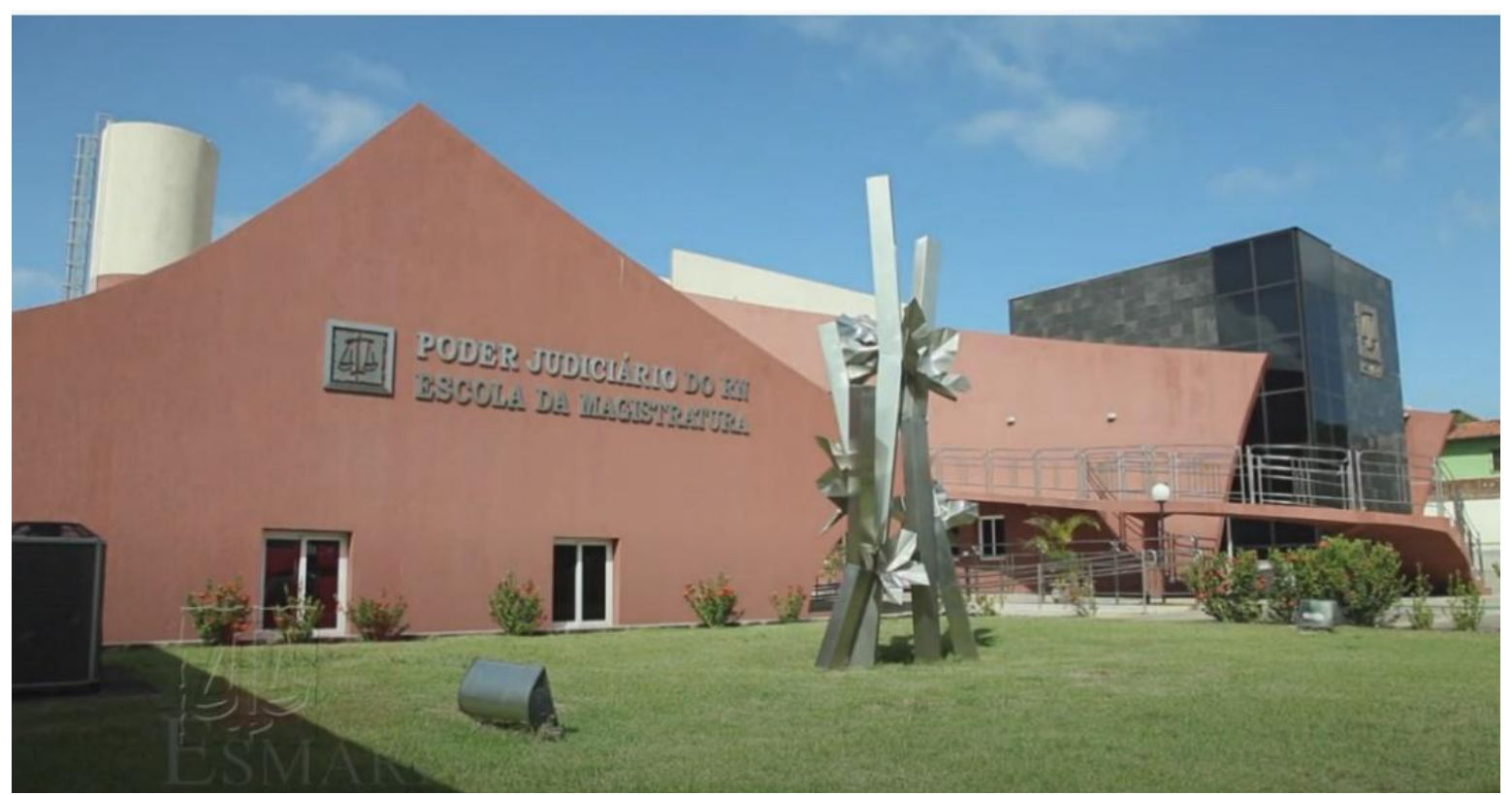

Fonte: Esmarn (2018).

O objetivo primordial dessa unidade de informação é colocar à disposição da comunidade jurídica, formada por desembargadores, magistrados e serventuários vinculados ao Poder Judiciário estadual e os profissionais da área jurídica, bem como estudantes que se preparam para concursos públicos, recursos e fontes de informações tanto em meios convencionais quanto em digitais, atualizados e compatíveis com a filosofia de ensino e aprendizagem da escola.

Nesse contexto, são desenvolvidos serviços variados que visam, em uníssono, organizar, processar e difundir repertórios científicos organizados para atender às necessidades de informação desse público. São oferecidos desde serviços técnicos, voltados para a normalização bibliográfica, a outros centrados na organização da informação, como catalogação e ordenação do acervo e serviços orientados para organizar o conhecimento, como as ações de classificação bibliográfica e indexação de documentos. São ofertados, ainda, serviços de levantamento e pesquisa bibliográfica na área jurídica, entre outros, característicos desse tipo de biblioteca. 


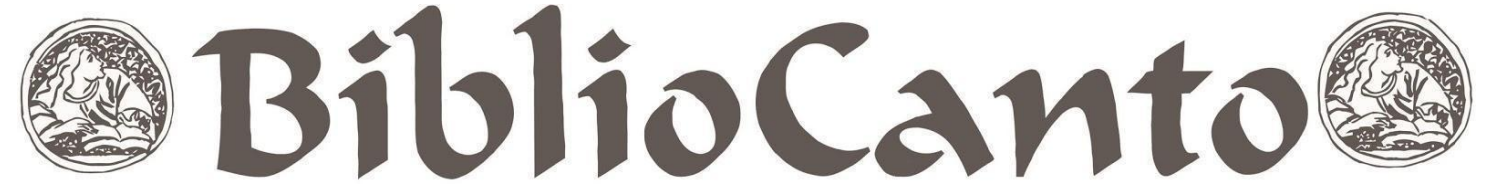

De forma geral, o foco dessa unidade de informação é o usuário, razão por que proporciona acesso à informação em meios convencionais (materiais impressos) e digitais (plataformas digitais e bases de dados em meio eletrônico).

Para alimentar continuamente o acervo, a referida biblioteca elabora projetos que visam à promoção ordenada, com a aquisição de materiais utilizando-se parâmetros, boas práticas e referenciais teóricos próprios contidos na área da Biblioteconomia e da Ciência da Informação. Essas ações são representadas por meio de projetos e programas específicos, como o PBJ.

\subsection{PROGRAMA BIBLIOTECA JURÍDICA}

Em 2013, a Esmarn deu um passo importante no sentido de aparelhar os órgãos jurisdicionais de primeiro e de segundo graus do Poder Judiciário do Rio Grande do Norte, com a proposta de atualizar seu acervo bibliográfico. Foi criado um programa denominado Programa Biblioteca Jurídica, por meio do Ato Normativo $n^{\circ}$ 2/2013, de 29 de janeiro de 2013, cujo objetivo primeiro era disponibilizar publicações jurídicas para auxiliar o trabalho diário dos magistrados por meio da aquisição de materiais bibliográficos (TRIBUNAL DE JUSTIÇA DO ESTADO DO RIO GRANDE DO NORTE, 2013).

De acordo com a Portaria $n^{\circ} 20 / 2017$, que revogou a Portaria $n^{\circ} 10 / 2013$ e só ampliou as unidades jurisdicionais contempladas com o programa, as obras são adquiridas por meio de licitação, em conformidade com a Lei $n^{\circ}$ 8.666/1993, e não devem ultrapassar o valor destinado por unidade jurisdicional (TRIBUNAL DE JUSTIÇA DO ESTADO DO RIO GRANDE DO NORTE, 2017). Contudo, as obras adquiridas por meio do PBJ pertencem à Escola, mas ficarão nos gabinetes, nas varas e nos setores do Poder Judiciário do $\mathrm{RN}$, que os solicitaram para propiciar um acesso rápido aos magistrados e aos assessores no trabalho diário, de acordo com suas especificidades e com a respectiva competência material. Isso significa que sua composição é determinada de acordo com a necessidade da equipe de trabalho de cada 


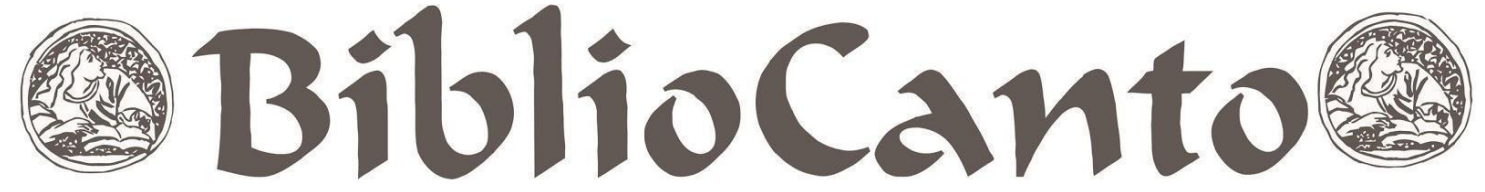

75

unidade jurisdicional, que, por intermédio do magistrado, indica o(s) livro(s) que Ihe interessam, adquiridos pela administração em licitações, com respeito ao valor limite estipulado em resolução.

A permanente modernização dos acervos da biblioteca e das unidades jurisdicionais constitui apoio fundamental para o exercício da magistratura e sua prática essencialmente social.

O programa funciona anualmente, com o objetivo de dotar os profissionais da Magistratura do que há de melhor em livros jurídicos e de fornecer informações para a produção de sentenças, votos e outras atividades judicantes. Vale ressaltar que não se trata de "auxílio-biblioteca", ou seja, não há repasse de verbas para desembargadores ou juízes.

A referida escola realiza licitação anual para adquirir livros tanto para a biblioteca da escola quanto para as unidades jurisdicionais solicitantes desse benefício. As obras adquiridas são tombadas por serem consideradas patrimônio. Entretanto, em sua gestão referente ao biênio 2019/2020, a Esmarn resolveu modernizar o $\mathrm{PBJ}$, com o intuito de abranger um número maior de unidades contempladas com o acervo mais vasto por meio de assinatura de Bibliotecas Digitais, uma vez que o aprimoramento intelectual da Magistratura é contínuo, e a atualização de conhecimentos reflete na qualidade da prestação jurisdicional.

Nas palavras de Severino Neto (REPORTAGEM..., 2020), chefe da Seção de Licitações e Contratos da Esmarn - TJRN, a aquisição das Bibliotecas Digitais foi um grande avanço para todos os colaboradores do Poder Judiciário, que, independentemente de sua unidade de lotação, passaram a ter acesso às 3.200 obras. Até o ano de 2019, quando a escola adquiria livros impressos, o que acontecia por causa dos pedidos de unidades judiciais localizadas em cidades distintas, às vezes eram adquiridas quatro a cinco unidades do mesmo livro. A realidade atual é diferente, o novo modelo de aquisição gera economia e acelera procedimentos internos (como tratamento técnico e eventual descarte), bem como dispensa deslocamento dos veículos para distribuir os livros em 64 cidades. 


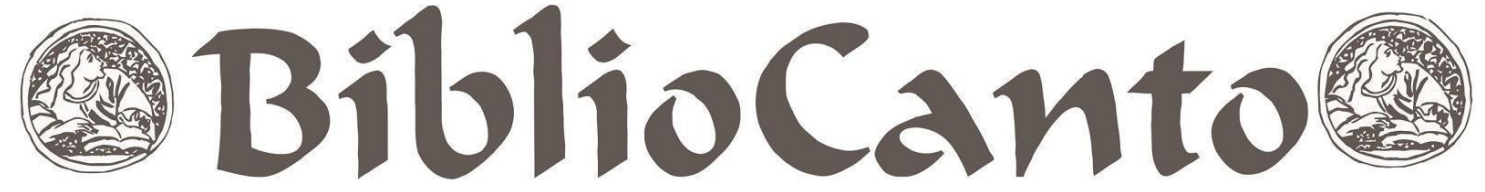

76

Severino Neto (REPORTAGEM..., 2020) também mencionou como vantagem de adquirir as plataformas digitais o fato de que "o livro físico é um livro físico a vida toda". Quanto aos livros digitais, se as edições forem atualizadas durante a vigência do contrato, teremos acesso ao conteúdo, mas não pagamos por elas. Essa é uma economia significativa de recursos públicos.

Assim, foram contratadas três Bibliotecas Digitais, em dezembro de 2019: 1) a Revista dos Tribunais Online Clássica - que disponibiliza 36 títulos de periódicos dos diversos campos do Direito; 2) a Biblioteca Proview, que permite acesso a uma coleção completa, com as obras dos selos editoriais (Revista dos Tribunais e Fiscosoft); e 3) a plataforma Minha Biblioteca, que propicia acesso aos livros técnicos e científicos publicados pelas editoras brasileiras: Grupo A, Grupo Gen-Atlas, Manole, Saraiva, Cengage Learning, Zahar, Grupo Autêntica, Editora Cortez, entre outras.

Embora exista a preferência por consultar livros físicos, o acesso remoto a informações, especialmente para quem reside no interior do estado do RN, por exemplo, e não tem como se deslocar para fazer suas pesquisas na sede da biblioteca, em Natal, constitui uma vantagem. Outra vantagem que a aquisição das bibliotecas digitais proporcionou ao Poder Judiciário do Estado foi contemplar, com informação jurídica e de áreas do conhecimento afins atualizadas, um universo maior de servidores, porque, antes, por meio do referido programa, só era possível adquirir livros para as unidades judiciárias solicitantes.

\section{METODOLOGIA}

Esta pesquisa é do tipo descritiva - com abordagem de cunho quantitativo - e tem como intuito traçar o perfil e satisfação dos usuários reais da Biblioteca Jurídica da Esmarn no tocante ao PBJ. Tal medida se faz necessária com vistas a melhorias na satisfação das necessidades de 


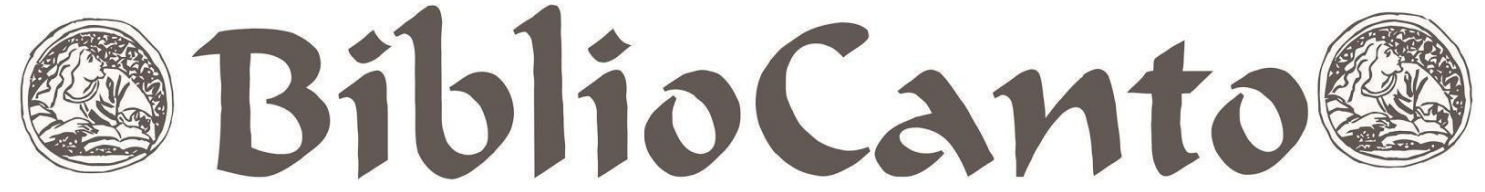

informação, servir a tomada de decisão nesse âmbito, bem como conferir transparência aos recursos públicos utilizados.

Iniciou-se com uma pesquisa bibliográfica pertinente aos temas investigados e com uma pesquisa documental. No tocante à parte empírica da pesquisa, o universo foram os magistrados, ou seja, juízes e assessores da referida instituição. Com vistas a coletar os dados, realizou-se uma pesquisa por meio da aplicação de um questionário eletrônico enviado por e-mail para os respondentes, usuários do $\mathrm{PBJ}$, contendo oito questões fechadas e uma aberta.

Os questionários foram enviados entre os meses de novembro e dezembro de 2018. Em seguida, procedeu-se à análise dos resultados obtidos, dando destaque aos três percentuais que obtiveram melhores índices de respostas, sendo, portanto, os apontamentos mais significativos para a pesquisa. Entretanto, deve-se observar que a soma de todas as alternativas de escolha corresponde a $100 \%$, como mostram os gráficos.

\section{ANÁLISE E DISCUSSÃO DOS RESULTADOS}

A fim de atender aos objetivos supracitados, ou seja, realizar um estudo de usuários da Biblioteca da Esmarn, idealizou-se uma pesquisa com os magistrados do Poder Judiciário do Estado do Rio Grande do Norte ${ }^{6}$. Para isso, aplicou-se um questionário eletrônico direcionado aos usuários do programa. Foram recebidos 79 questionários, o que representa $32,1 \%$ do total do quadro de 246 magistrados.

No processo de análise e discussão dos resultados obtidos, as respostas às questões fechadas e de múltipla escolha foram organizadas em conformidade com as oito perguntas e tabuladas estatisticamente, sendo apresentadas por meio de gráficos e tabelas juntamente com percentuais e

\footnotetext{
${ }^{6}$ Esta pesquisa é complementar a uma outra que visava analisar o grau de satisfação de um público mais abrangente, usuários da Biblioteca Desembargador José Gomes da Costa, não enfatizando especificamente o caso dos magistrados, que se encontra disponível em: https://revistas.ufrj.br/index.php/rca/article/view/34641/21690.
} 


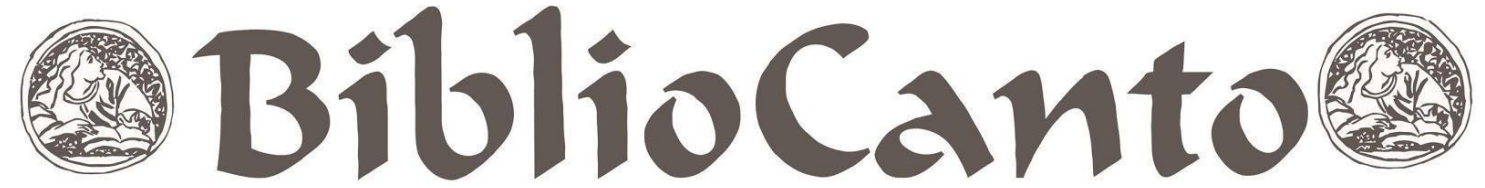

análises descritivas, seguidas de comentários dos resultados, de modo a permitir a verificação dos objetivos propostos pela pesquisa, sequenciando pelos de comentários dos resultados.

Na perspectiva de Marconi e Lakatos (2021), os gráficos representam os dados obtidos por meio de figuras, demonstrando aspectos visuais para fácil compreensão. No tocante às tabelas, as autoras destacam ser um método estatístico sistemático, para apresentação de dados em colunas verticais ou fileiras horizontais, uma vez que facilitam, ao leitor, o entendimento e interpretação rápida dos dados.

As primeiras perguntas visavam identificar o perfil dos magistrados do Poder Judiciário do RN, levando em consideração as seguintes variáveis: gênero, faixa etária, nível de formação acadêmica e a região de atuação no $\mathrm{RN}$.

Quanto à variável gênero, pode-se afirmar que existe um equilíbrio na amostra, com uma pequena predominância dos respondentes femininos, que correspondem a $51,9 \%$, ao passo que o quantitativo masculino foi de $48,1 \%$.

No que diz respeito à faixa etária do grupo, constatou-se que $53,2 \%$ dos magistrados têm idades entre 36 e 45 anos; 24,1\%, entre 46 e 55 anos; 11,4\%, entre 25 e 35 anos; 8,9\%, entre 56 e 65; e 2,4\%, entre 66 e 75 anos, como demonstrado no Gráfico 1. Portanto, considerando-se os dados apresentados, pode-se inferir que mais da metade dos informantes da pesquisa têm idades entre 36 e 45 anos.

Gráfico 1 - Faixa etária

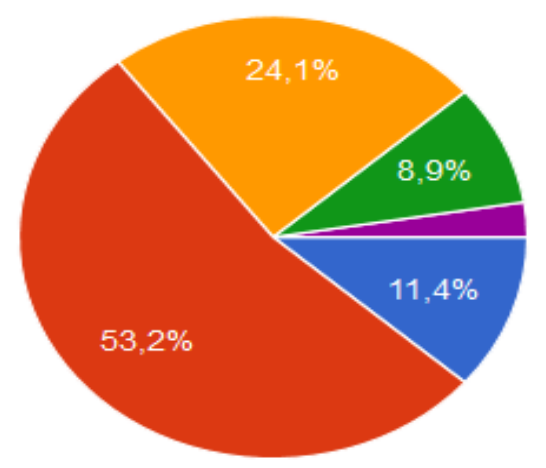

Fonte: Dados da pesquisa (2018). 
Quanto à terceira questão - sobre o nível de formação acadêmica dos magistrados -, obtiveram-se os seguintes resultados: $54,4 \%$ são especialistas; 25,3\% são graduados; $12,7 \%$ cursaram doutorado, e 7,6\%, mestrado (Gráfico 2). Portanto, a maioria dos magistrados do estado fez algum curso em nível de pós-graduação. Quando perguntados se tinham uma segunda graduação, 8,9\% afirmaram ter concluído outra faculdade.

\section{Gráfico 2 - Formação acadêmica}

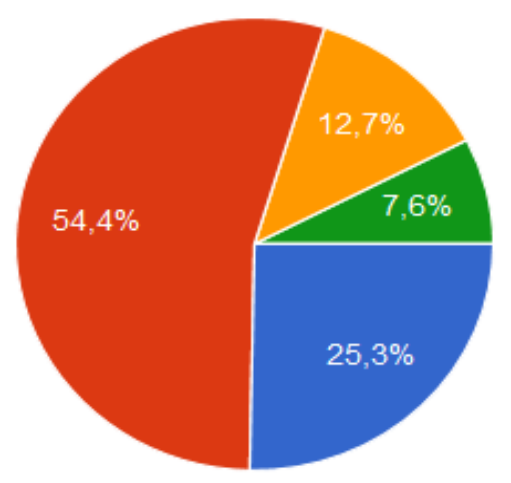

Graduação

Pós-graduação (Especialização ou MBA)

Pós-graduação (Mestrado)

Pós-graduação (Doutorado).

Fonte: Dados da pesquisa (2018).

Ainda sobre o conhecimento do perfil dos magistrados - em se tratando da região de atuação no Estado, na quinta pergunta -, constatou-se que a maioria $(46,8 \%)$ exerce suas atividades profissionais nos municípios do interior, $39,2 \%$ trabalham na capital do estado, Natal, e 13,9\% executam seus afazeres profissionais na região metropolitana, conforme mostra o Gráfico 3. Esses resultados demonstram que a quantidade de juízes que exercem suas atribuições é superior no interior. Por outro lado, se considerados os municípios de Natal e os da região metropolitana - a grande Natal -, esse cenário muda para $53,1 \%$, superando o percentual dos magistrados atuantes no interior. 
Gráfico 3 - Região de atuação

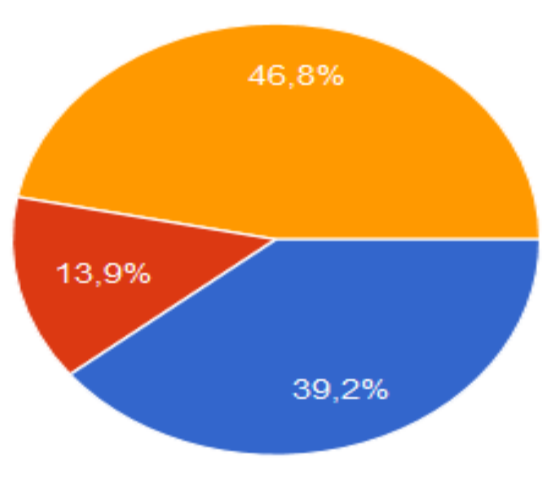

Região metropolitana

Interior

Fonte: Dados da pesquisa (2018).

Dando continuidade ao estudo, procurou-se identificar o nível de satisfação com algumas facetas do PBJ. Nessa questão, disponibilizou-se uma lista com cinco quesitos elencados referentes aos procedimentos realizados no PBJ versus o nível de satisfação dos respondentes, conforme apresentado na Tabela 1.

Tabela 1 - Nível de satisfação relativo aos procedimentos do PBJ

\begin{tabular}{lccccc}
\hline Característica & $\begin{array}{c}\text { Muito } \\
\text { insatisfeito }\end{array}$ & Insatisfeito & $\begin{array}{c}\text { Razoavelmente } \\
\text { satisfeito }\end{array}$ & Satisfeito & $\begin{array}{c}\text { Muito } \\
\text { satisfeito }\end{array}$ \\
\hline $\begin{array}{l}\text { Valor } \\
\text { destinado } \\
\text { para aquisição }\end{array}$ & $1,27 \%$ & $7,59 \%$ & $24,05 \%$ & $49,37 \%$ & $17,72 \%$ \\
$\begin{array}{l}\text { Prazo de } \\
\text { pedido }\end{array}$ & $2,53 \%$ & $12,66 \%$ & $32,91 \%$ & $44,30 \%$ & $7,59 \%$ \\
$\begin{array}{l}\text { Prazo de } \\
\text { entrega }\end{array}$ & $16,46 \%$ & $35,44 \%$ & $30,38 \%$ & $15,19 \%$ & $2,53 \%$ \\
$\begin{array}{l}\text { Meio de } \\
\text { recebimento }\end{array}$ & $6,33 \%$ & $13,92 \%$ & $17,72 \%$ & $48,10 \%$ & $13,92 \%$ \\
& & & & &
\end{tabular}


Fonte: Dados da pesquisa (2018).

De acordo com os resultados obtidos na pesquisa - mostrados na referida Tabela -, os níveis de satisfação relativos ao andamento dos processos do PBJ mais elevados entre os cinco quesitos investigados, considerando as respostas simultâneas das opções "satisfeito" e "muito satisfeito", foram os seguintes: divulgação da abertura do PBJ, com 70,89\%, e o valor destinado para aquisição, com $67,09 \%$. Já os itens avaliados com níveis de satisfação mais baixos, considerando as respostas "insatisfeito" e "muito insatisfeito", foram estes: prazo de entrega, com 51,9\%, e meio de recebimento, com $20,25 \%$.

No que diz respeito à insatisfação, ficou evidente, na sétima questão, que o prazo de entrega se deve ao trâmite do procedimento de aquisição das obras, porque existem formalização de licitação, campanha de divulgação de abertura do PBJ e recebimento e cadastramento das solicitações das unidades judiciais para fazer o pedido de compra ao fornecedor, fatos que contribuem para o atraso na entrega. Quanto à insatisfação referente ao meio de entrega, esta deve-se à dificuldade com as unidades localizadas no interior do RN.

\section{Gráfico 5 - Nota atribuída ao programa}

30

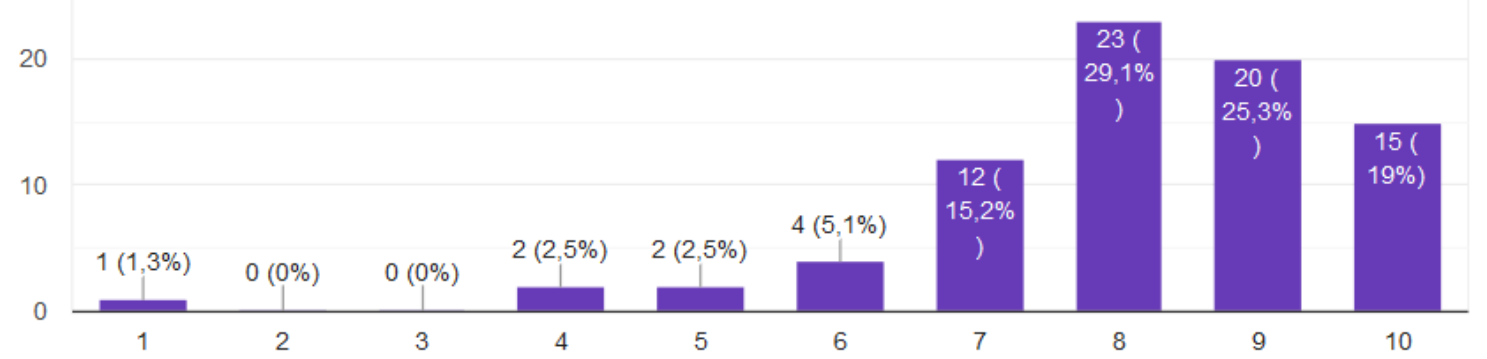

Fonte: Dados da pesquisa (2018). 


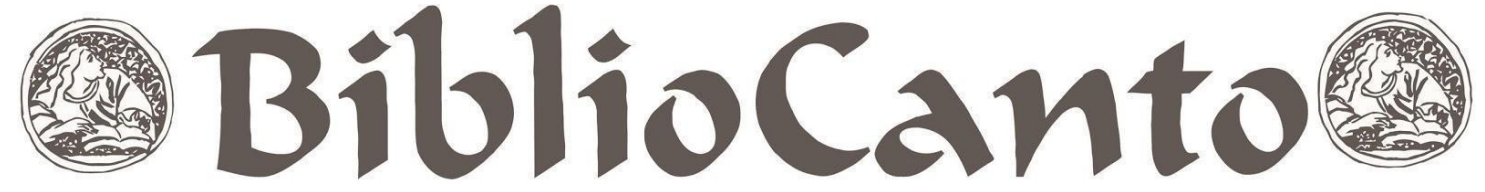

82

Continuando a análise, buscou-se obter dos magistrados a atribuição de uma nota de 1 a 10 ao PBJ, conforme representado no Gráfico 5 . Os resultados indicaram que eles demonstraram estar satisfeitos, visto que as notas com índices maiores foram 8 (29,1\%), 9 (25,3\%) e 10 (19\%). Vê-se que a maioria dos sujeitos da pesquisa avaliou o PBJ com conceito bom, embora tal programa, na concepção dos magistrados, ainda necessite de algumas melhorias para atingir um patamar mais elevado. Desse modo, fica evidente que o PBJ outorga acesso a um acervo especializado na área jurídica de atuação do magistrado, possibilitando a disseminação da informação, contribuindo efetivamente para a tomada de decisão das sentenças proferidas por esses profissionais. Identificou-se que os respondentes indicaram a assinatura de bibliotecas digitais que se adéquam à realidade das unidades jurídicas.

É possível afirmar que o referido programa instrumentaliza os usuários com informações fidedignas e de qualidade e que estas, potencialmente, podem se transformar em conhecimento, beneficiando a sociedade como um todo.

\section{CONSIDERAÇÕES FINAIS}

Esta pesquisa objetivou a realização de um estudo de usuários com vistas a promover um panorama da satisfação dos magistrados do Poder Judiciário do estado Rio Grande do Norte em relação ao PBJ. Partiu-se da necessidade de propiciar um relato de experiência que pode ser potencialmente aproveitado em outros contextos semelhantes, bem como de publicizar o uso de recursos públicos empregados no contexto desafiador de gestão de coleções na pandemia atual. Adicionalmente e como forma de dar sustentação à proposta, foram discutidos conceitos operatórios no campo.

Percebe-se que, na atual conjuntura, as unidades de informação, como as bibliotecas jurídicas, têm um papel fundamental de promover o acesso à informação e, por conseguinte, contribuem para que o importante campo das 
Ciências Jurídicas evolua com o potencial de gerar repercussão em variadas esferas da sociedade. O estudo mostrou que, para garantir a qualidade dos serviços prestados por essas bibliotecas, é importante criar produtos e estratégias que auxiliem o atendimento dos seus objetivos.

A aplicação do questionário, via web, e da metodologia adotada nesta pesquisa, possibilitou a obtenção de uma amostra significativa de participantes em um curto espaço de tempo e a avaliação de vários aspectos quanto à satisfação dos informantes da pesquisa, além de conhecer o perfil dos magistrados.

A pesquisa permitiu conhecer melhor as opiniões dos sujeitos em relação aos seguintes quesitos: relevância, satisfação e sugestões de melhorias no desenvolvimento do PBJ, de modo geral, mostrando que o programa tem conseguido cumprir seu papel.

Os resultados apresentados demonstraram que a informação jurídica é um recurso importante para a sociedade e para os magistrados. O referido programa é uma ação importante para disseminar a informação jurídica do Poder Judiciário do Estado do Rio Grande do Norte, devido ao papel de subsidiar e de promover o acesso a esse recurso para os usuários envolvidos, colocando à disposição uma vasta gama de doutrina, jurisprudência, súmulas e legislação atualizada, propiciando o avanço no aprimoramento intelectual da magistratura e dos servidores. Portanto, é um importante investimento institucional que propicia continuamente a atualização de conhecimentos que podem gerar inovação nesse campo e refletir na qualidade da prestação jurisdicional.

Nessa perspectiva, este estudo pretendeu servir como instrumento de suporte para a gestão da Biblioteca Desembargador José Gomes da Costa. E como é a primeira pesquisa dessa natureza realizada na referida instituição, poderá ser utilizada para nortear várias tomadas de decisão no âmbito da gestão, na elaboração de estratégias de aquisição de coleções e no atendimento às necessidades de informação dos juízes. 
Com base na pesquisa realizada, é possível inferir que programas como o PBJ têm sido um dos meios de distribuir a matéria-prima da biblioteca e informação jurídica de boa qualidade, que funciona como um elemento que agrega valor e possibilita ao magistrado o apoio necessário para cumprir seu papel relevante na sociedade.

Abstract: The article aims to propose a user study in order to analyze the satisfaction of judges in the context of the Library of the School of Magistracy of Rio Grande do Norte (ESMARN) in Brazil, regarding the Legal Library Program (PBJ), which proposes strategies aimed at acquiring bibliographic and non-bibliographic material in this context and the consequent socialization of legal information in that institution. In order to contextualize the subject, a bibliographical research was carried out, regarding themes such as legal information and user studies. Aiming to charcterize the locus of the research, a description of the referred school was made regarding its historical aspects, characterization, its information unit and the referred program, its objectives, among other aspects. The methodology is descriptive, with a quantitative approach. As for the empirical part of the work, the research characterized the user community with a view to analyzing the level of satisfaction related to different aspects of the PBJ. Data was collected through a questionnaire applied to the population of program users (judges). In the end, it was possible to infer that the program achieved user satisfaction on behalf of the magistrates, fulfills its main function - that of promoting access to quality legal information. Finally, it indicates the need for periodic evaluations of the program aiming to guaranteeing the provision of good quality services and the fulfillment of organizational objectives, as well as providing transparency in the use of public resources.

Keywords: Legal Library Program. User studies. Legal Information - Magistrate School. 


\section{REFERÊNCIAS}

ANDRADE, Maria Laura. Bibliotecas jurídicas: saberes y orientaciones prácticas. Buenos Aires: Editorial Dunken, 2017.

ARAÚJO, Carlos Alberto Ávila. Estudos de usuários conforme o paradigma social da Ciência da Informação: desafios teóricos e práticos de pesquisa. Inf. Inf., Londrina, v. 15, n. 2, p. 23-39, 2010. Disponível em: https://bit.ly/2AYUNou. Acesso em: 12 jun. 2020.

ARAÚJO, Carlos Alberto Ávila. O sujeito informacional no cruzamento da Ciência da Informação com as ciências humanas e sociais. In: ENCONTRO NACIONAL DE PESQUISA EM CIÊNCIA DA INFORMAÇÃO, 14., 2013, Florianópolis. Anais [...]. Florianópolis, UFSC, 2013. Disponível em: https://bit.ly/316eqG4. Acesso em: 23 jun. 2020.

ATIENZA, Cecília Andreotti. Documentação jurídica: introdução à análise e indexação de atos legais. Rio de Janeiro: Achiamé, 1979.

BARROS, Lucivaldo. Fontes de informação jurídica. In: PASSOS, Edilenice (org.). Informação jurídica: teoria e prática. Brasília: Thesaurus, 2004. Cap. 9. p. 201-225.

BRASIL. Emenda constitucional $\mathbf{n}^{\circ} \mathbf{4 5}$, de 30 de dezembro de 2004. Altera dispositivos dos arts. $5^{\circ}, 36,52,92,93,95,98,99,102,103,104,105,107$, 109, 111, 112, 114, 115, 125, 126, 127, 128, 129, 134 e 168 da Constituição Federal, e acrescenta os arts. 103-A, 103B, 111-A e 130-A, e dá outras providências. Disponível em:

http://www.planalto.gov.br/ccivil_03/constituicao/emendas/emc/emc45.htm. Acesso em: 30 jun. 2020.

BRASIL. Lei $\mathbf{n}^{\circ} \mathbf{8 . 6 6 6}$, de 21 de junho de 1993. Regulamenta o art. 37, inciso XXI, da Constituição Federal, institui normas para licitações e contratos da Administração Pública e dá outras providências. 1993. Disponível em: http://www.planalto.gov.br/ccivil_03/leis/L8666compilado.htm. Acesso em: 30 jun. 2020.

CUNHA, Murilo Bastos da; AMARAL, Sueli Angélica do; DANTAS, Edmundo Brandão. Manual de estudo de usuários da informação. São Paulo: Atlas, 2015.

FIGUEIREDO, Nice. Estudo de uso e usuários da informação. Brasília: Ibict, 1994. 
GONZÁLEZ TERUEL, Aurora. Los estudios de necesidades y usos de información: fundamentos y perspectivas actuales. Gijón: Trea, 2005.

GUIMARÃES, José Augusto Chaves. La información jurídica. In: BARITÉ, Mario. Guia metodológica para el acceso, el análisis y la organización temática de documentos jurídicos. Montevideo: Universidad de La República, 1999. p. 11-18.

GUINCHAT, Claire; MENOU, Michael. Introdução geral às ciências e técnicas da informação e documentação. Brasília: Ibict, 1994.

KOURY, Suzy Cavalcante. Planejamento estratégico do poder judiciário: o papel das escolas judiciais. Revista do Tribunal Regional do Trabalho da $\mathbf{9}^{\text {a }}$ Região, Curitiba, v. 35, n. 64, p. 343-356, jan./jun. 2010. Disponível em: https://bit.ly/38f9111. Acesso em: 1 jul. 2020.

KUHLTHAU, Carol Collier. Inside the search process: information seeking from the user's perspective. JASIST, v. 42, n. 5, p. 361-371, 1991. Disponível em: https://bit.ly/2NoDYX2. Acesso em 23 jun. 2020.

MARCONI, Marina de Andrade; LAKATOS, Eva. Maria. Fundamentos de metodologia científica. 9. ed. São Paulo: Atlas, 2021.

MIRANDA, Ana Cláudia Carvalho de; D’AMORE, Ticiano M.; PINTO, Virgínia Bentes. Gestão documental da informação jurídica. Perspectivas em Ciência da Informação, Belo Horizonte, v. 18, n. 3, p. 96-110, jul./set. 2013. Disponível em: https://bit.ly/2BSulb7. Acesso em: 30 jun. 2020.

MIRANDA, Ana Cláudia Carvalho de; MIRANDA, Erlano Silva de. Fontes de informação jurídica. Encontros Bibli: Revista Eletrônica de Biblioteconomia e Ciência da Informação, Florianóplis, v. 22, n. 50, p. 76-90, set./dez. 2017. Disponível em: https://bit.ly/3gc7uLJ. Acesso em: 30 jun. 2020.

PASSOS, Edilenice. O controle da informação jurídica no Brasil: a contribuição do Senado Federal. Ci. Inf., Brasília, v. 23, n. 3, p. 363-368, set./dez. 1994. Disponível em: https://bit.ly/3inwsdh. Acesso em: 23 jun. 2020.

REPORTAGEM sobre as plataformas da Biblioteca Virtual Esmarn.

Entrevistado: Francisco Severino Neto. Natal: Escola da Magistratura do Rio Grande do Norte, 2020. 1 vídeo (4 min). Publicado pelo canal Esmarn Oficial. Disponível em:

https://www.youtube.com/watch?v=6Jrk9hs5N9E\&feature=youtu.be. Acesso em: 30 jul. 2020.

RIO GRANDE DO NORTE. Lei Estadual $\mathbf{n}^{\circ}$ 6.370, de 20 de janeiro de 1993. Dispõe sobre a organização da Secretaria e dos serviços auxiliares do TJRN e definiu as diretrizes gerais para sua reforma e modernização administrativa.

Diário Oficial do Estado: Natal, 21 jan. 2014. 
TARAPANOFF, Kira. Técnicas para tomada de decisão nos sistemas de informação. 3. ed. Brasília: Thesaurus, 2004.

TRIBUNAL DE JUSTIÇA DO RIO GRANDE DO NORTE (TJRN). Escola da Magistratura do Rio Grande do Norte (ESMARN). Ato Normativo $n^{\circ}$ 02/2013, de 29 de jan. de 2013. Institui o Programa Biblioteca Jurídica, gerido pela Escola da Magistratura do Estado do Rio Grande do Norte - ESMARN, e disciplina a forma de aquisição de acervos bibliográficos e não bibliográficos para aparelhar os órgãos jurisdicionais do Poder Judiciário do Estado do Rio Grande do Norte, a Presidência, a Vice-Presidência, Redação Judiciária e a Corregedoria. Diário da Justiça [RN]: Escola da Magistratura, Natal, RN, ano 7, edição 1258, 31 jan. 2013.

TRIBUNAL DE JUSTIÇA DO RIO GRANDE DO NORTE (TJRN). Escola da Magistratura do Rio Grande do Norte (ESMARN). Portaria n² 20/2017, de 02 de março de 2017. Estabelece o valor anual destinado ao Programa Biblioteca Jurídica, que visa aparelhar as unidades jurisdicionais, a Presidência, a Vice-Presidência, a Redação Judiciária, a Corregedoria, a Divisão dos Precatórios, a CAPJ e os CEJUSCs de acervo bibliográfico necessário à permanente atualização de seus titulares, membros da Instituição. Diário da Justiça [RN]: Escola da Magistratura, Natal, RN, ano 11, edição 2245, 07 mar. 2017.

TRIBUNAL DE JUSTIÇA DO RIO GRANDE DO NORTE (TJRN). Resolução n 08-TJ, de 06 de maio de 2020. Atribui o nome de Desembargador Manoel de Araújo Silva à Escola da Magistratura do Rio Grande do Norte. Diário da Justiça [RN]: Secretaria Geral, Natal, RN, ano 14, edição 3002, 06 maio 2020.

TRIBUNAL DE JUSTIÇA DO RIO GRANDE DO NORTE (TJRN). Resolução nº 05/88-TJ, de 09 de dezembro de 1988. Cria a Escola Superior da Magistratura do Estado do Rio Grande do Norte e dá outras providências. Diário Oficial do Estado do Rio Grande do Norte: TJRN, Natal, RN, nº 6.943, 09 dez. 1988.

TRIBUNAL DE JUSTIÇA DO RIO GRANDE DO NORTE (TJRN). Resolução nº 07/98-TJ, de 09 de setembro de 1998. Dispõe sobre a Escola da Magistratura do Rio Grande do Norte - ESMARN, que regulamenta o Curso de Formação Inicial dos Magistrados e dá outras providências. Diário Oficial do Estado do Rio Grande do Norte: TJRN, Natal, RN, 9 set. 1998.

WILSON, Tom D. Revisiting user studies and information needs. Journal of Documentation, 2006. Disponível em: https://bit.ly/2YZkptv. Acesso em: 23 jun. 2020. 